\title{
Insulin regulation of a novel WD-40 repeat protein in adipocytes
}

\author{
B D Rodgers ${ }^{1,2}$, M A Levine ${ }^{2}$, M Bernier ${ }^{1}$ and \\ C Montrose-Rafizadeh ${ }^{1}$
}

${ }^{1}$ Diabetes Section, Gerontology Research Center, National Institute on Aging, National Institutes of Health, 5600 Nathan Shock Drive, Baltimore, Maryland 21224, USA

${ }^{2}$ Division of Pediatric Endocrinology, Johns Hopkins University School of Medicine, 600 North Wolfe Street, Park 211, Baltimore, Maryland 21287, USA

(Requests for offprints should be addressed to B D Rodgers, Pediatric Endocrinology, Johns Hopkins University School of Medicine, 600 North Wolfe Street, Park 211, Baltimore, Maryland 21287, USA; Email: drodgers@jhmi.edu)

\begin{abstract}
A $400 \mathrm{bp}$ PCR product generated with degenerate primers derived from the glucagon-like peptide-1 receptor was used to screen a rat skeletal muscle cDNA library. The predicted amino acid sequence of the $978 \mathrm{bp}$ open reading frame has a predicted $M_{\mathrm{r}}$ of 35804 , an estimated isoelectric point (pI) of 5.31 and contains seven WD-40 repeats, which are common to G-protein beta subunits $(G \beta)$. Although chemically and structurally similar to G $\beta$ subunits, the predicted amino acid sequence, when compared with the previously cloned G $\beta$ isoforms, was found to be only $31-41 \%$ similar and thus was named G $\beta$-like (GßL, 'Gable'). Western blotting of whole-cell lysates and immunoprecipitates of membrane and cytosolic fractions of HEK 293 cells stably overexpressing a carboxy-terminal His-tagged G $\beta \mathrm{L}$ indicates that the protein is cytosolic and that it migrates at $42 \mathrm{kDa}$. A $4 \mathrm{~kb}$ transcript was detected in all tissues surveyed by northern blotting; however, an additional $2 \mathrm{~kb}$ transcript was detected in testis. Expression
\end{abstract}

of G $\beta L$ mRNA was highest in the brain and testis, followed by lung, heart, kidney, skeletal muscle, spleen and liver. In addition, reverse transcriptase/PCR showed that several other tissues and cell lines express G $\beta L$. The ubiquitous nature of the tissue expression pattern of $\mathrm{G} \beta \mathrm{L}$ is similar to that of the insulin receptor, which suggests that insulin may influence GßL expression. Indeed, G $\beta \mathrm{L}$ protein and mRNA levels, in fully differentiated 3T3-L1 adipocytes, were upregulated by insulin in a concentration-dependent fashion. These changes were highly sensitive to insulin stimulation, being minimally affected by doses as low as $0.1 \mathrm{nM}$ and maximally elevated by $1 \mathrm{nM}$ doses. These data suggest that insulin regulates $\mathrm{G} \beta \mathrm{L}$ production and imply that some of the actions of insulin may be mediated, in part, by this novel intracellular protein.

Journal of Endocrinology (2001) 168, 325-332

\section{Introduction}

Members of the WD-40 family of eukaryotic proteins help to regulate intracellular signaling, RNA processing and degradation, gene expression, vesicular traffic and fusion, cytoskeletal assembly, and the cell cycle (van der Voorn \& Ploegh 1992, Neer et al. 1994, Garcia et al. 1996). The earliest identified and most well-known members are the beta subunits of heterotrimeric guanine nucleotidebinding proteins ( $G \beta$ subunits of $G$-proteins). To date, five mammalian genes that encode $G \beta$ isoforms have been identified. The corresponding proteins are highly homologous and all contain seven equally well-conserved WD-40 motifs (Hamm \& Gilchrist 1996).

All proteins within the WD-40 family contain repeating sequences that are separated by approximately 40 amino acids. Each WD-40 repeat consists of two signature sites: a poorly conserved site A that usually contains a glycine and histidine $(\mathrm{GH})$ pair and a relatively well-conserved site B that usually contains a tryptophan and aspartate (WD) pair. Although every WD-40 family member contains four to eight of these repeating motifs, the separating distance and the actual sequence of individual repeats are highly variable. Most of these sites are separated by 36-46 amino acids; however, they are often separated by over 50 . The functional diversity of WD-40 proteins suggests that the motif itself does not necessarily confer any particular function; rather, it contributes to the formation of antiparallel $\beta$-strands that stabilize three-dimensional loops or $\beta$-propellers (van der Voorn \& Ploegh 1992, Neer et al. 1994, Garcia et al. 1996). Although functionally distinct, many of these structural cognates form multiprotein complexes via non-covalent linkages between their $\beta$-propellers and other proteins including intracellular effectors, enzymes or even transmembrane receptors.

In an attempt to identify new G-protein coupled receptors (GPCRs) in muscle, rat heart cDNA was analyzed by a PCR with degenerate primers against the glucagon-like peptide-1 receptor. One of the resulting PCR products contained several regions that were signifi- 
cantly homologous to $G \beta$ subunits and to other proteins within the WD-40 superfamily. Reported herein is the isolation and characterization of a novel cDNA clone named G $\beta L$ ('Gable'), for G $\beta$-like, whose protein and mRNA levels are upregulated by insulin.

\section{Materials and Methods}

\section{Isolation of $c D N A$ clones encoding $G \beta L$}

Total RNA from cardiac and skeletal muscle was extracted using guanidine thiocyanate and $\mathrm{CsCl}$-centrifugation (Chirgwin et al. 1979). Reverse transcriptase/PCR (RTPCR) was performed with Moloney murine leukemia virus reverse transcriptase and oligo-dT primers (both from GibcoBRL/Life Technology, Gaithersburg, MD, USA) in the first reaction and in the second with recombinant Amplitaq DNA polymerase (Perkin-Elmer, Gaithersburg, MD, USA) and degenerate primers against the extracellular domain of the glucagon-like peptide-1 (GLP-1) receptor (forward, 5'-GTCGAATTG (EcoRI) GAA/G TAT/C A/CGI CAT/C CAA/G TGT/C C-3'; reverse, 5'-GCTCTAGA (XbaI) CCA/G TCC CAT/C TGA/G TGT/C TGT/C TG-3'). The amplification products were subcloned into pBluescript KS to obtain pHB1 following digestion with EcoRI and XbaI (GibcoBRL/Life Technology) and were eventually used to screen a Uni-Zap XR skeletal muscle cDNA library (Stratagene, La Jolla, CA, USA). Several partial clones of approximately $1.6 \mathrm{~kb}$ were isolated and each was found to contain the $3^{\prime}$-untranslated region (UTR) and a portion of the polyadenylated tail. Part of the remaining upstream sequence was determined with the 5' RACE (rapid amplification of cDNA ends) system (GibcoBRL/Life Technology) using the following gene-specific primers (GSPs): GSP1, 5'-ccg gca cta ttg act gcc gc-3'; GSP2, 5'-GCG CAC TGT GTG GTC ATA GCC TGC-3'; GSP3, 5'-CGGGATCC (BamHI) CGG TGG TAT TCA TTG TTT GAT GGC-3'. An additional 299 bp of the 5 '-UTR were identified by genome walking (Clontech, Palo Alto, CA, USA) with GSP2 and GSP4 (5'CGGGATCC (BamHI) CGC TCT GCA CTC TGC CTT AGT C-3'). All PCR products were subcloned into pBluescript KS following digestion with BamHI and SalI.

\section{Tissue distribution of $G \beta L$ expression}

A multiple-tissue northern blot (Clontech) containing mRNA from rat heart, brain, spleen, lung, liver, skeletal muscle, kidney and testis was probed with the radiolabeled pHB1 insert following EcoRI/XbaI digestion. Band intensities were quantified by electronic autoradiography (Packard Instruments, Meriden, CT, USA). G $\beta \mathrm{L}$ expression was also identified by non-quantitative RT-PCR of total RNA from rat epididymal, abdominal and brown fat, small intestine, and pancreas, as well as from 3T3-L1 fibroblasts and adipocytes, L6-myotubes, Chinese hamster ovary $(\mathrm{CHO})$ cells and rat insulinoma cells, as described above with primers internal to pHB1 (forward, 5'-CTG CAC GGC TCG CAT CTG GG-3'; reverse, 5'-CCG GCA CTA TTG ACT GCC GC-3').

\section{Characterization of $G \beta L$ antiserum}

Anti $(\alpha)-G \beta L$ was generated against a dodecapeptide (KSSNPGESSRGW) that is located within the carboxyterminal region of $G \beta L$ and is not contained within any other known proteins, as determined by a BLAST search. The antigenic peptide was cross-linked to BSA (BSA-pep) with bis (2-(succinimidooxy-carbonyoxy)-ethyl) sulfone (Pierce, Rockford, IL, USA). BSA-pep was then subsequently cross-linked to epoxy aminohexate sepharose with $\mathrm{N}$-ethyl-N'-(3-dimethylaminopropyl) carbodiimide $\mathrm{HCl}$ and used to affinity-purify $\alpha$ G $\beta \mathrm{L}$. BSA and BSA-pep (75 and $7.5 \mathrm{pmol}$ ) were then immunoprecipitated in the absence or presence of a fivefold excess of competing peptide in RIPA buffer $(50 \mathrm{mM}$ Hepes $(\mathrm{pH} 7 \cdot 4)$, $267.6 \mathrm{mM} \mathrm{NaCl}, 2 \%$ Nonidet P-40, 0.2\% Na dodecyl sulfate (SDS), $1 \%$ Na-deoxycholate, $2 \mathrm{mM} \quad \mathrm{Na}-$ orthovanadate, $200 \mathrm{mM} \mathrm{NaF}, 1 \mathrm{mM}$ benzamidine, $1 \mathrm{mM}$ Pefabloc, $2 \mu \mathrm{g} / \mathrm{ml}$ leupeptin and $8 \mu \mathrm{g} / \mathrm{ml}$ aprotinin) containing protein $\mathrm{A} / \mathrm{G}$ agarose that was preblocked in $0 \cdot 1 \%$ BSA. Immunoprecipitated proteins were separated by means of reducing SDS-PAGE on $4-12 \%$ gradient gels and transferred onto $0 \cdot 2 \mu \mathrm{m}$ polyvinylidene difluoride (PVDF) membranes (all from Novex, Gaithersburg, MS, USA). The membranes were blocked in 5\% non-fat milk prepared in $20 \mathrm{mM}$ Tris. $\mathrm{HCl}$ (pH 7.5), $137 \mathrm{mM} \mathrm{NaCl}$ and $0 \cdot 1 \%$ Tween-20 (TBST), probed with affinitypurified $\alpha \mathrm{G} \beta \mathrm{L}(1: 2000)$ in $1 \%$ non-fat milk and then probed with horseradish peroxidase (HRP)-conjugated goat anti-rabbit antiserum (HRP-GAR, 1:5000; Amersham, Piscataway, NJ, USA) in TBST. Positive immunogenic reactions were visualized with Enhanced Chemiluminescence (ECL) detection reagents (Amersham).

\section{Transfection of HEK 293 cells}

Full-length rat G $\beta \mathrm{L}$ cDNA was generated by RT-PCR amplification of $5 \mu \mathrm{g}$ rat brain RNA with gene-specific primers (forward, 5'-CTA AGG CAG AGT GCA GAG CG-3'; reverse, 5'-GCC CAG CAC GCT GTC GTT G-3'). After an initial denaturation at $94^{\circ} \mathrm{C}$ for 4 min, rat brain cDNA was amplified by PCR for 30 cycles of the following regime: $94{ }^{\circ} \mathrm{C}$ for $30 \mathrm{~s}, 60^{\circ} \mathrm{C}$ for $30 \mathrm{~s}$, and $72{ }^{\circ} \mathrm{C}$ for $1 \mathrm{~min}$. G $\beta \mathrm{L}$ cDNA was then gel-purified and subcloned into the pcDNA3.1-V5/His/TOPO TA cloning vector (pcDNA31-GßL/V5/His). HEK 293 cells were plated in Dulbecco's Minimal Essential Medium (DMEM) supplemented with 10\% fetal bovine serum 
(FBS). Once they were $70 \%$ confluent in $25 \mathrm{~mm}^{2}$ flasks, cells were preincubated for $1 \mathrm{~h}$ in serum-free DMEM and transfected with $2.7 \mu \mathrm{g}$ pcDNA31-G $\beta \mathrm{L} / \mathrm{V} 5 / \mathrm{His}$ and Lipofectamine Plus reagent (GibcoBRL/Life Technology). The transfection was terminated after $3 \mathrm{~h}$ by replacing the serum-free DMEM with DMEM/10\% FBS. A polyclonal stable cell line was derived by the addition of $500 \mu \mathrm{g} / \mathrm{ml} \mathrm{G} 418$ to the culture medium $48 \mathrm{~h}$ after transfection and by subsequently culturing these cells in the presence of G418 for approximately 3 weeks.

\section{Western blotting and immunoprecipitation}

Whole-cell lysates from wild-type and transfected cells were solubilized in $1.5 \times$ reducing SDS-PAGE sample buffer and analyzed by Western blotting as described. To determine the cellular localization of $\mathrm{G} \beta \mathrm{L}$, transfected cells were washed three times in PBS and quickly frozen in liquid nitrogen. Cells were then scraped in a cell suspension buffer containing $20 \mathrm{mM}$ Hepes ( $\mathrm{pH} 7 \cdot 6$ ), $150 \mathrm{mM}$ $\mathrm{NaCl}, 5 \mathrm{mM} \mathrm{MgCl} 2,1 \mathrm{mM}$ EDTA, $1 \mathrm{mM}$ benzamidine, $1 \mathrm{mM}$ Pefabloc, $2 \mu \mathrm{g} / \mathrm{ml}$ leupeptin and $8 \mu \mathrm{g} / \mathrm{ml}$ aprotinin and sheared through a 26-gauge needle. Lysates were then incubated on ice for $30 \mathrm{~min}$ with $20 \mu \mathrm{g} / \mathrm{ml}$ DNase I before centrifugation at $20000 \times \boldsymbol{g}$ for $30 \mathrm{~min}$ at $4{ }^{\circ} \mathrm{C}$. The supernatant (cytosolic fraction) was then removed and CHAPSO was added to a final volume of $0.5 \%$; the pelleted membrane fraction was then solubilized in the cell suspension buffer supplemented with $0 \cdot 5 \%$ CHAPSO to a volume equal to that of the supernatant $(1 \mathrm{ml})$ and centrifuged for an additional $15 \mathrm{~min}$. Non-specific proteins from both crude fractions were first precleared with G $\beta$ L preimmune serum (1:500) for $1 \mathrm{~h}$ at room temperature. Each fraction was then immunoprecipitated with $\alpha G \beta L$ (1:500), also for $1 \mathrm{~h}$ at room temperature. Wholecell lysates and immunoprecipitated proteins were separated on 4-12\% SDS-polyacrylamide gels and analyzed by western blotting with either HRP-conjugated anti $(\alpha)$ V5 or with $\alpha G \beta L$ as described above. The membrane harboring whole-cell lysates alone was first blotted with $\alpha \mathrm{V} 5$ HRP, stripped (Chemicon, Temecula, CA, USA) and reblotted with $\alpha G \beta L$. To confirm sufficient stripping of $\alpha$ V5-HRP, ECL reagents were applied to the membrane before reprobing with $\alpha G \beta L$.

\section{Insulin regulation of $G \beta L$ production in 3T3-L1 adipocytes}

3T3-L1 preadipocytes were cultured in DMEM supplemented with $10 \%$ calf serum until 2 days post-confluency. Differentiation was induced by the addition of $0.5 \mathrm{mM}$ isobutylmethylxanthine, $1 \mathrm{mM}$ dexamethasone and $167 \mathrm{nM}$ insulin to DMEM that was supplemented with $10 \%$ FBS. Cells were then incubated for 2 days in this differentiation medium, for 2 days in DMEM/10\% FBS with insulin and for 2 days in DMEM/10\% FBS. Fully differentiated cells were then preincubated for $48 \mathrm{~h}$ in serum-free DMEM before the addition of $0,0 \cdot 01,0 \cdot 1,1$, 10 and $100 \mathrm{nM}$ insulin. After incubation for $16 \mathrm{~h}$, cells were washed three times in PBS, rapidly frozen in liquid nitrogen, scraped and solubilized in $1.5 \times$ reducing sample buffer and then analyzed by western blotting with antisera

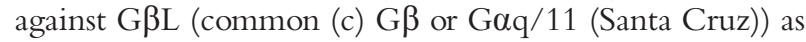
described above.

Changes in G $\beta \mathrm{L}$ mRNA levels were determined by semi-quantitative RT-PCR. RNA $(5 \mu \mathrm{g})$ from each sample was reversed-transcribed as described above. Before amplification of sample cDNA, the linear portion of the amplification curves for actin and $G \beta L$ transcripts were first defined by cycle titration PCR on control-cell cDNA with GSPs (actin forward, 5'-TAT GGA GAA GAT TTG GCA CC-3'; actin reverse, 5'-TCA TCG TAC TCC TGC TTG $\mathrm{C}-3^{\prime}$; $\mathrm{G} \beta \mathrm{L}=\mathrm{pHB} 1$ primers as above). Once the optimal cycle number had been identified, $10 \mu \mathrm{l}$ cDNA from each sample was diluted into aliquots of a PCR master-mix buffer containing $50 \mu \mathrm{M}$ dNTP, $2.5 \mathrm{U}$ Taq and $0.04 \mu \mathrm{Ci}\left[{ }^{32} \mathrm{P}\right]$ deoxycytosine triphosphate $/ \mu \mathrm{l}$ (Amersham). Samples were then divided in half before the addition of actin- or G $\beta \mathrm{L}$-specific primers (to a final concentration of $0 \cdot 2 \mu \mathrm{M}$ ) and were then amplified separately (actin, 25 cycles of $94^{\circ} \mathrm{C}$ for $30 \mathrm{~s}, 58^{\circ} \mathrm{C}$ for $30 \mathrm{~s}$ and $72{ }^{\circ} \mathrm{C}$ for $1 \mathrm{~min}$; G $\beta \mathrm{L}, 32$ cycles). Amplicons were resolved on $6 \%$ polyacrylamide Tris-borate EDTA gels, which were subsequently dried and exposed to film.

\section{Statistical analysis}

Differences between the means were determined by ANOVA coupled to Fisher's Least Significance Difference for multiple mean comparisons. G $\beta \mathrm{L}$ transcript levels were normalized to those of actin, and each insulin dose was repeated four separate times. Interassay variation was controlled by expressing 'treated' values as percentages of the controls.

\section{Results}

\section{Isolation and analysis of $G \beta L C D N A$ clones}

A $400 \mathrm{bp}$ PCR product was isolated using degenerate primers derived from the GLP-1 receptor. From this product, an internal $256 \mathrm{bp}$ subsequence was used to isolate several partial clones of approximately $1.4-1.6 \mathrm{~kb}$ from a rat skeletal muscle cDNA library. Three of the largest clones were sequenced and each contained a large, but incomplete, open reading frame, the putative $3^{\prime}$-UTR with the polyadenylation signal sequence and 18 nucleotides of the poly(A) tail (Fig. 1). An additional $370 \mathrm{bp}$ was obtained by 5 ' RACE, and the remaining portion of the $5^{\prime}$-UTR (Fig. 1, italics), which could not be amplified by RT-PCR, was obtained by genome walking. The accession number of this sequence has been deposited in the GenBank database (accession no. AF051155). 
$-360$

-350 GGTTGGTAGG GTAGAGGATT

-210 TGACAGCCAC TCCGCGCACG

-140 CCCACTCCCT GGACCCATGG

-70 GACTCGCTCC TGCTCGCCTC
GTGTATGTCG GTTGGGGGTG AAGGGCAACG CAGCAGCACC GTGTTTGTAG TTCCCATGA ATCACTTCTG GAGTTCTTCA TCTCAGAACT TCTCGCCCGG AGTTACTATC GATAACTCTA GCCGTCCTGG ACTAAGGCAG AGTGCAGAGC
ATTCTAGCT'

ACAGTGTAAT TCTTTCTTGE TTCAAGGCTG AGGTCGCGGC CTCTTATCCT TGTCAACTCC CGCTCGGCCC GGCTTCTATC GTGTGTTAAG CCATCAAACA

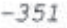

$-281$

$-211$ $-141$ $-71$

$-1$

$\begin{array}{llllllllllllllllllllll}1 & M & N & T & T & P & G & T & V & G & \text { S } & \text { D } & \text { P } & \text { V } & \text { I } & \text { I } & \text { A } & \text { T } & \text { A } & \text { G } & \text { Y } & 20\end{array}$

1 ATG AAT ACC ACC CCA GGC ACA GTG GGC AGT GAC CCT GTC ATC TTA GCA ACT GCA GGC TAT 60 $\begin{array}{lllllllllllllllllllll}D & H & T & V & R & F & \text { W } & Q & \text { A } & \text { H } & \text { S } & G & \text { I } & \text { C } & \text { T } & \text { R } & \text { T } & \text { V } & Q & H & 40\end{array}$ GAC CAC ACA GTG CGC TTT TGG CAG GCT CAC AGT GGA ATC TGC ACT CGA ACA GTG CÁ CAT 120 $\begin{array}{llllllllllllllllllllll}Q & D & S & Q & V & N & A & L & E & I & T & P & D & R & S & M & I & A & A & T & 60\end{array}$ CAg GAC TCT CAG GTG AAT GCA TTG GAG ATC ACT CCA GAC CGg AGC ATG ATT GCT GCT ACA 180

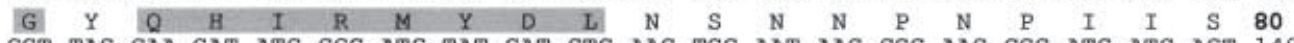
GGT TAC CAA CAT ATC CGC ATG TAT GAT CTC AAC TCC AAT AAC CCC AAC CCC ATC ATC AGT 140 $\begin{array}{lllllllllllllllllllll}\text { Y } & D & G & V & S & K & N & I & A & S & V & G & F & H & E & D & G & R & W & M & 100\end{array}$ TAT GAC GGA GTC AGT AAG AAC ATC GCA TCA GTG GGT TTT CAT GAG GAT GGC CGC TGG ATG 300 $\begin{array}{lllllllllllllllllllll}Y & T & G & G & E & D & C & T & A & R & I & W & D & L & R & S & R & N & L & Q & 120\end{array}$ TAT ACA GGT GGA GAG GAC TGC ACG GCT CGC ATC TGG GAC CTC AGG TCC CGG AAC CTG CAG 360 $\begin{array}{ccccccccccccccccccccc}\text { C } & Q & \text { R } & \text { I } & \text { F } & \text { Q } & \text { V } & \text { N } & \text { A } & \text { P } & \text { I } & \text { N } & \text { C } & \text { V } & \text { C } & \text { L } & \text { H } & \text { P } & \text { N } & Q & 140 \\ \text { TGT } & \text { CAG } & \text { CGT } & \text { ATC } & \text { TTC } & \text { CAG } & \text { GTG } & \text { AAT } & \text { GCA } & \text { CCC } & \text { ATT } & \text { AAT } & \text { TGC } & \text { GTG } & \text { TGT } & \text { CTA } & \text { CAT } & \text { CCC } & \text { AAC } & \text { CAG } & 420\end{array}$ $\begin{array}{lllllllllllllllllllll}\text { A } & \text { E } & \text { L } & \text { I } & \text { V } & \text { G } & \text { D } & \text { Q } & \text { S } & G & \text { T } & \text { S } & \text { H } & \text { I } & \text { W } & D & \text { L } & \text { K } & \text { T } & \text { D } & 160\end{array}$ GCA GAA CTC ATC GTG GGT GAC CAG AGC GGC ACG AGC CAC ATC TGG GAC CTG AAG ACA GAC 480

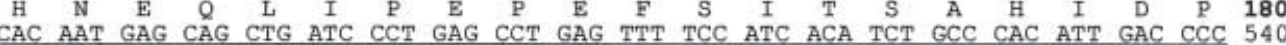

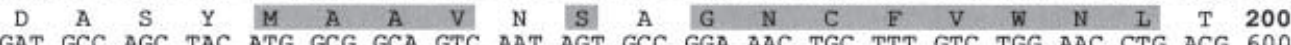

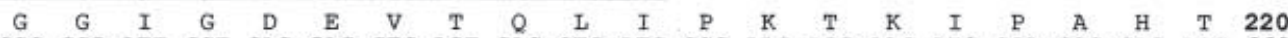
GGG GGC ATT GGT GAC GAG GTG ACT CAG CTC ATC CCC AAG ACC AAG ATC CCA GCC CAC ACG 660 $\begin{array}{ccccccccccccccccccccc}\text { R } & \text { Y } & \text { A } & \text { L } & \text { Q } & \text { C } & \text { R } & \text { F } & \text { S } & \text { P } & \text { D } & \text { S } & \text { T } & \text { L } & \text { I } & \text { A } & \text { T } & \text { C } & \text { S } & \text { A } & 240\end{array}$ $\begin{array}{lllllllllllllllllllll}D & Q & T & C & K & I & W & R & T & S & N & F & S & L & M & T & E & L & S & I & 260\end{array}$ GAC CAG ACG TGT AAA ATC TGG AGG ACA TCC AAC TTC TCC CTG ATG ACA GAA CTC AGC ATC 780

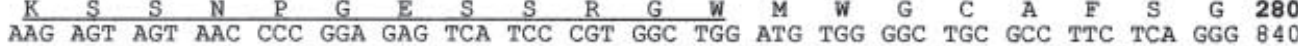
$\begin{array}{ccccccccccccccccccccc}D & S & Q & Y & I & V & T & A & S & S & D & N & L & A & R & L & W & C & \text { V } & \text { E } & 300\end{array}$ GCT TCT TCA GAC AAC CTG GCC CGG CTC TGG TGT GTA GAG 900

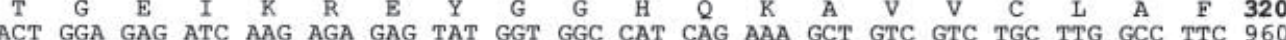

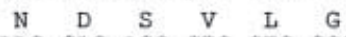
AAC GAC AGC GTG CTG GGC

CСССTGCCC CTTGAGGGCT CCTGGTCTAG TGGCTCTAAG TGCATATCAG GCCAGTGGGA ACTCTACCCT GGGACTTTCT CTGGATTGGG AGTCTTCTCC GTTGATGCCT GTATCCCAGA AGAGGTGCTT ACCTTGGAAG AGTGTCAGCA TCAGCAGCAA ACAGTACTAG CTGTGGGGCT GGTAGGTGGT GACTCCTGTC CTCAACAGGC TTGGACCTGA ATGCACTGAT TGTCTGCAGC ACTGTATCCT CCCCTCCCAA GACAACCC'TC TCCCCCACTT ATGGGATTTT GGAGTGTGTG TGTCTGGTTG GGCAGATTTT TAAAGGGGTA TGAACCATCA

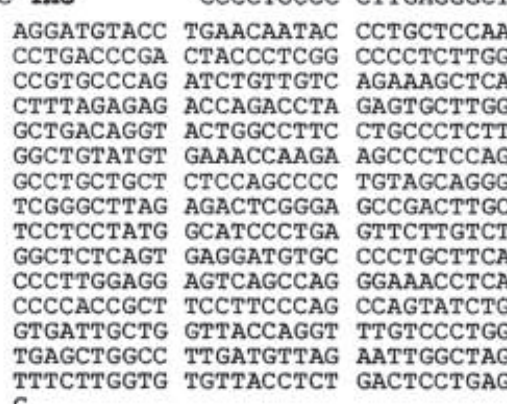
AGGATGTACC TGAACAATAC CCTGCTCCAA CCGTGCCCAG ATCTGTTGTC AGAAAGCTCA CTTTAGAGAG ACCAGACCTA GAGTGCTTGG GGCTGTATGT GAAACCAAGA AGCCCTCCAG GCCTGCTGCT CTCCAGCCCC TGTAGCAGG TCGGGCTTAG AGACTCGGGA GCCGACTTGC GGCTCTCAGT GAGGATGTGC CCCTGCTTCA CCCTTGGAGG AGTCAGCCAG GGAAACCTCA GTGATTGCTG GTTACCAGGT TTGTCCCTGG TTTCTTGGTG TGTTACCTCT GACTCCTGAG

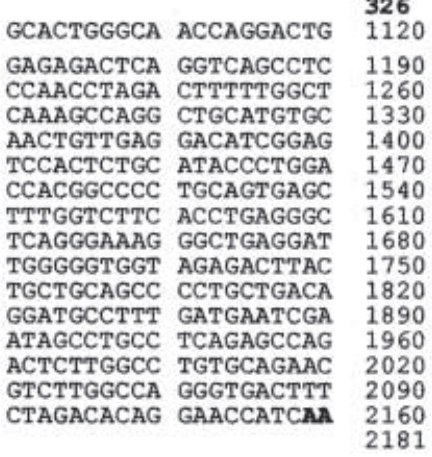

Figure 1 Nucleotide and predicted amino acid sequence of G $\beta L$ cDNA. Nucleotide numbering is relative to the adenosine in the initiator codon. Amino acid numbering (bold) is relative to the first methionine. The $5^{\prime}$-UTR sequence isolated from genomic DNA is shown in italics, residues fulfilling the site B portion of the WD-40 repeats are shaded, and in-frame stop codons and the polyadenylation signal sequence are in bold. The cDNA probe sequence used for Northern blotting and library screening and the immunogenic epitope used in generating $\alpha G \beta L$ are shown underlined.

The G $\beta L$ open reading frame of $978 \mathrm{bp}$ codes for a protein of 326 amino acids and contains a sufficient Kozak sequence surrounding the initiator codon (Kozak 1996). The predicted amino acid sequence of the GßL protein has a calculated $M_{\mathrm{r}}$ of 35804 and an estimated isoelectric point (pI) of $5 \cdot 31$, properties that are similar to those of previously identified $G \beta$ isoforms (Hamm \& Gilchrist
1996). It contains seven WD-40 motifs that are separated from each other by $42-50$ amino acids (Fig. 1). BLAST analysis of the G $\beta \mathrm{L}$ nucleotide or amino acid sequence indicates that it shares significant homology with many WD-40-containing proteins, including the five mammalian G $\beta$ subunits. However, G $\beta$ L is only $24-32 \%$ identical and $31-41 \%$ similar to $G \beta 1-5$ overall and most of 
these homologies are limited to the WD-40 site B motifs $(5 \Phi \mathrm{x}(\mathrm{D} / \mathrm{N} / \mathrm{K}) \mathrm{xx} \Phi \mathrm{x} \Phi(\mathrm{W} / \mathrm{F} / \mathrm{Y})(\mathrm{D} / \mathrm{N} / \mathrm{E} / \mathrm{R} / \mathrm{K}) \delta$ where $\Phi=$ hydrophobic \& A,T,G,S; $\mathrm{x}=$ any; $\delta=$ non-charged) which are relatively well conserved (residues 15, 16) (Fig. 1, shaded). Potential 'GH' motifs of WD-40 site A $\left(\Phi_{x}(G / \Phi)(H / K) x x x \Phi_{x x} \Phi\right)$ were also identified upstream of the last six site B motifs. These are AH (residues 29, 30), SK (residues 85, 86), LH (residues 136, 137), AH (residues 176, 177), AH (residues 218, 219) and IK (residues 260, 261).

BLAST analysis of the Expressed Sequence Tags (EST) database identified partial sequences of the putative mouse (accession no. AA396503) and human (accession no. F12722) G $\beta$ L homologues whose partial amino acid sequences were 96 and $93 \%$ identical to rat $\mathrm{G} \beta \mathrm{L}$, respectively. The mouse clone was subsequently obtained from the Integrative Molecular Analysis of Gene Expression (IMAGE) Consortium and the Washington University Genome Sequencing Center in St Louis, MO, USA, and was sequenced at the Johns Hopkins University DNA Analysis Facility. Thereafter, the full-length sequence was deposited in the GenBank database (accession no. AF237676). The open reading frame of the mouse cDNA clone is $98.5 \%$ homologous to rat GBL cDNA, and the predicted proteins are $99 \%$ identical. The partial human GBL EST clone was isolated serendipitously by the generation of a transcriptional map for exonic regions adjacent to the polycystic kidney disease 1 gene and was mapped to human chromosome 16p13.3 (Burn et al. 1996). Screening of the human genome database identified the remaining portion of the human $G \beta L$ open reading frame as well as the surrounding intronic and promoter sequences (GenBank accession no. AC009065). The predicted amino acid sequence of this putative homologue is $96.6 \%$ identical to rat G $\beta L$ overall. In fact, the carboxyterminal 204 residues of both proteins are indistinguishable. These data strongly suggest that the G $\beta \mathrm{L}$ homologues are extremely well conserved among mammals. BLAST analysis also identified a yeast (Saccharomyces cerevisiae) cDNA sequence that encodes a basic protein named POP3, whose mass is $22.6 \mathrm{kDa}$. Although slightly smaller than G $\beta$ L, the predicted proteins are $60.4 \%$ similar and $44 \%$ identical overall. Moreover, these homologies are not limited to the WD-40 repeating motifs, but are evenly distributed throughout.

\section{G $\beta L m R N A$ tissue distribution}

Northern blot analysis (Fig. 2) using a radiolabeled cDNA probe (Fig. 1) identified a $4 \mathrm{~kb}$ transcript in most tissues and an additional $2 \mathrm{~kb}$ transcript in testis and in $\mathrm{CHO}$ cells (data not shown). G $\beta \mathrm{L}$ mRNA was expressed abundantly in all tissues assayed, but was highest in testis and brain followed (in decreasing order) by lung, heart, kidney, skeletal muscle, spleen and liver. Additionally, RT-PCR (data not shown) showed that GBL was expressed in rat

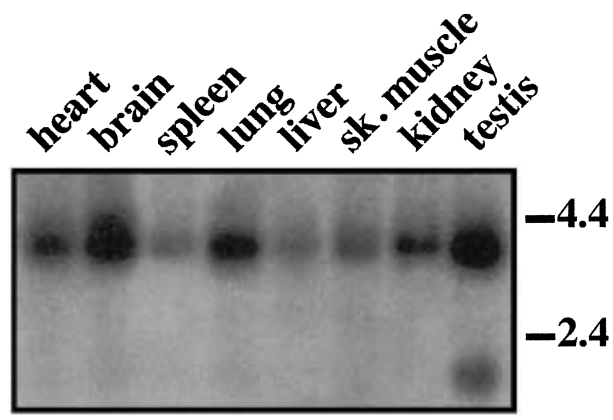

Figure 2 Tissue distribution of $G \beta L$ transcripts. A northern blot of poly $(\mathrm{A})+\mathrm{RNA}(2 \mu \mathrm{g} / \mathrm{lane})$ from the indicated rat tissues was hybridized with a G $\beta$ L-specific radiolabeled probe (Fig. 1) as described in the Materials and Methods. RNA size standards are indicated on the right $(\mathrm{kb})$.

epididymal, abdominal and brown fat, small intestine, pancreas, 3T3-L1 fibroblasts and adipocytes, L6-myotubes and in rat insulinoma (RIN1046-38) cells.

\section{Western blotting and immunoprecipitation of $\mathrm{G} \beta L$}

Antiserum against G $\beta \mathrm{L}(\alpha \mathrm{G} \beta \mathrm{L})$ was characterized by immunoprecipitating the antigenic peptide that was crosslinked to BSA (BSA-pep). The addition of excess peptide during the immunoprecipitation reaction displaced much of the BSA-pep within the immunoprecipitate (Fig. 3A). Therefore, $\alpha G \beta L$ specifically recognizes the antigenic peptide. Antiserum against the V5 epitope $(\alpha \mathrm{V} 5)$ and $\alpha \mathrm{G} \beta \mathrm{L}$ both recognized single proteins of $42 \mathrm{kDa}$ in HEK 293 cells overexpressing a carboxy-terminal epitopetagged G $\beta \mathrm{L} / \mathrm{V} 5 /$ His fusion protein (Fig. 3B), indicating that G $\beta \mathrm{L}$ migrates slightly slower than its predicted mass of $36 \mathrm{kDa}$. This band was not recognized by preimmune serum (data not shown). In addition, western blotting of $\alpha G \beta L$ immunoprecipitates from crude membrane and cytosolic fractions indicated that the $42 \mathrm{kDa}$ epitopetagged G $\beta \mathrm{L}$ is located predominantly within the cytosol (Fig. 3C, left panel). Several bands within the immunoprecipitates were recognized by $\alpha \mathrm{V} 5-\mathrm{HRP}$ in addition to the $42 \mathrm{kDa}$ band that represents G $\beta \mathrm{L}$. These additional bands were not detected during probing of whole-cell lysates (Fig. 3C, middle panel); they were detected, however, during probing of $\alpha \mathrm{G} \beta \mathrm{L}$ alone that was not used to immunoprecipitate (Fig. 3C, right panel). Thus, these additional bands are due to the cross-reaction of $\alpha$ V5-HRP to $\alpha \mathrm{G} \beta \mathrm{L}$.

\section{Insulin regulation of $G \beta L$ production}

The insulin receptor and G $\beta$ L both appear to be similarly distributed in many different tissues; therefore, the ability of insulin to regulate $\mathrm{G} \beta \mathrm{L}$ production was investigated. $\mathrm{G} \alpha \mathrm{q} / 11, c G \beta$ and $\mathrm{G} \beta \mathrm{L}$ protein levels were measured in 

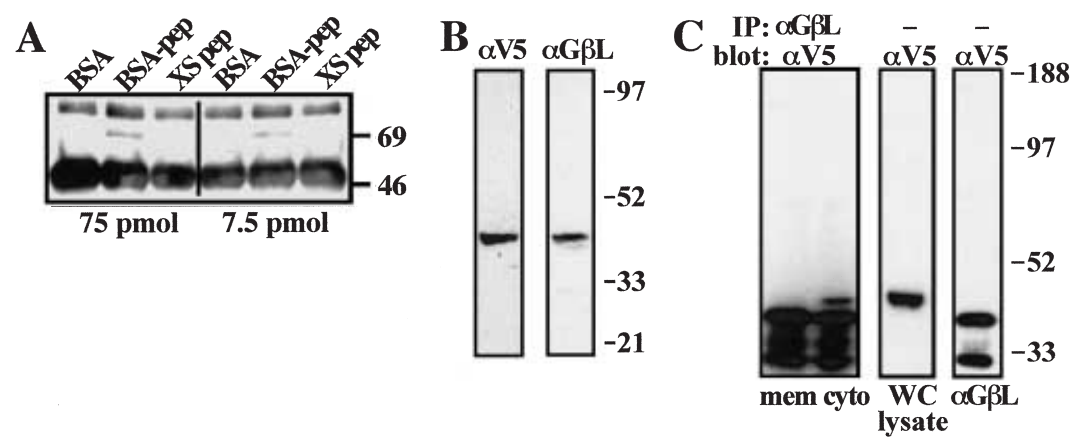

Figure 3 Western blotting and immunoprecipitation studies. (A) $7 \cdot 5$ and 75 pmol of BSA alone or BSA-conjugated antigenic peptide (BSA-pep) were immunoprecipitated with $\alpha \mathrm{G} \beta \mathrm{L}$ in the absence or presence (XS pep) of antigenic peptide. Immunoprecipitates were analyzed by Western blotting with $\alpha \mathrm{G} \beta \mathrm{L}$, as described in the Materials and Methods. (B) Western blotting of whole-cell lysates from HEK 293 cells overexpressing an epitope-tagged (V5/His) G $\beta$ L. The membrane was first probed with $\alpha \mathrm{V} 5$-HRP (left) then stripped and reprobed with $\alpha \mathrm{G} \beta \mathrm{L}$ (right). (C) Crude cytosolic (cyto) and membrane (mem) fractions from transfected cells were immunoprecipitated with $\alpha \mathrm{G} \beta \mathrm{L}$ and the precipitated proteins were analyzed by Western blotting with $\alpha \mathrm{V} 5$-HRP (left panel). Whole-cell lysates from these cells (middle panel) as well $\alpha G \beta L$ that was not used in an immunoprecipitation reaction (right panel) were also analyzed by Western blotting with $\alpha \mathrm{V} 5$-HRP. The data presented in the latter two panels indicate that the 30-40 kDa bands present in the left panel are due to the cross-reaction of $\alpha \mathrm{V} 5$ - HRP to the immunoprecipitating immunoglobulin G, $\alpha \mathrm{G} \beta \mathrm{L}$.

fully differentiated 3T3-L1 adipocytes that were stimulated with varying concentrations of insulin. Although the $\mathrm{G} \alpha \mathrm{q} / 11$ and cG $\beta$ levels were unaffected by insulin, $\mathrm{G} \beta \mathrm{L}$ protein levels were elevated in a concentration-dependent manner (Fig. 4A; representative blots of two separate experiments are shown). 3T3-L1 adipocytes were sensitive to doses of insulin as low as $0 \cdot 1 \mathrm{nM}$ and were maximally stimulated at $1 \mathrm{nM}$. In order to compare G $\beta \mathrm{L}$ mRNA values between treatment groups by semi-quantitative RT-PCR, the linear portion of the amplification curve for both $G \beta L$ and actin transcripts was first identified (Fig. 4B). Samples were then amplified for a particular number of cycles that would allow for changes within the linear range $($ actin $=25, G \beta L=32$ ) and $G \beta L$ transcript values were then normalized to those of actin. Insulin raised the G $\beta \mathrm{L}$ transcript levels in a concentration-dependent manner and the effect was maximal at concentrations at or above $1 \mathrm{nM}$ insulin (Fig. 4C). Therefore, 3T3-L1 adipocytes appeared to be sensitive to concentrations of insulin of less than $1 \mathrm{nM}$. Changes in G $\beta \mathrm{L}$ mRNA levels were similar to the changes in protein levels; thus, the ability of insulin to upregulate $G \beta L$ production is not due to an increase in translational efficiency per se, but appears to be due either to increased G $\beta \mathrm{L}$ gene transcription or to increased transcript stability.

\section{Discussion}

G $\beta L$ possesses many structural features that are characteristic of $G \beta$ subunits, including a similar molecular weight and isoelectric point as well as the presence of seven WD-40 repeating motifs. However, the low overall homology between G $\beta L$ and any of the known G $\beta$ proteins suggests that $G \beta L$, unlike many of the mammalian $G \beta$ subunits, did not originate from the same ancestral gene and is therefore not a legitimate $G \beta$ homologue. However, BLAST analysis did identify a yeast ribonucleoprotein, POP3, whose amino acid sequence is $60.4 \%$ similar and $44 \%$ identical to rat $\mathrm{G} \beta \mathrm{L}$. POP3 is a protein component of yeast RNase mitochondrial RNA processing and RNase P. These RNA-protein complexes are responsible for the post-transcriptional modification of primary rRNA and tRNA transcripts respectively. Although the level of homology shared by these two proteins does not necessarily suggest that they are true orthologues, it is indicative of functional conservation and suggests that $G \beta L$ may either interact directly with RNA or even function as (or in conjunction with) an endoribonuclease.

Insulin is capable of altering the expression of many genes, both at a transcriptional and post-transcriptional level. Specifically, insulin stimulation increases the stability of farnesyltransferase $\alpha$ - and $\beta$-subunit message, which ultimately facilitates the farnesylation and membrane incorporation of p21 Ras (Goalstone \& Draznin 1998, 1999). The metabolic actions of insulin are mediated, in part, by similar increases in glycerol 3-phosphate dehydrogenase and glucokinase mRNA stability (Iynedjian et al. 1989, Bhandari et al. 1991). Of particular interest is the ability of insulin to inhibit gluconeogenesis by inducing phosphoenolpyruvate carboxykinase (PEPCK) mRNA degradation (Christ et al. 1988, 1990, Heise et al. 1998). This 
B. cycle \#: 2025303540
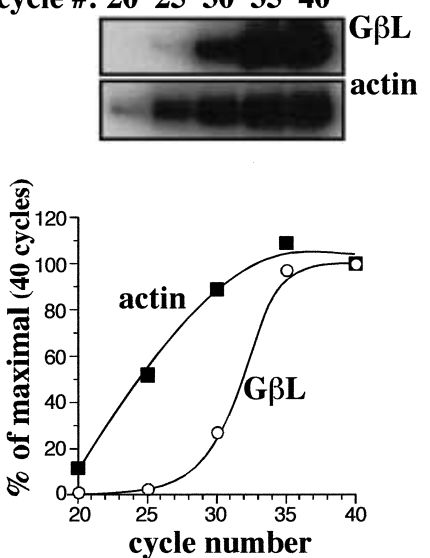

A. insulin (M): $0 \quad 0,0,0,0,0,0$

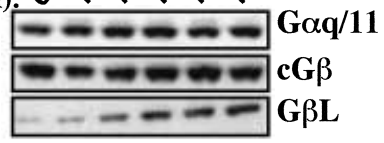

C. insulin (M): 0 O
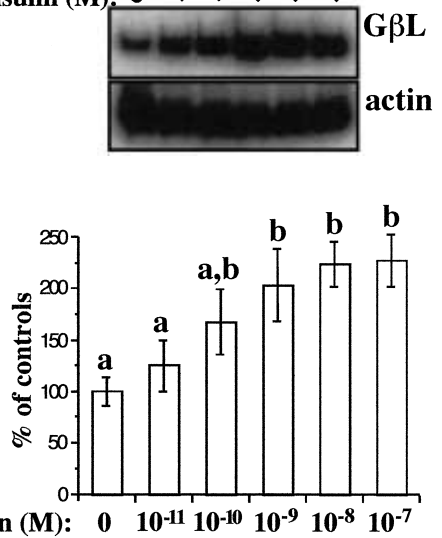

Figure 4 Insulin regulation of G $\beta$ L production. (A) Fully differentiated 3T3-L1 adipocytes were serum-starved for $48 \mathrm{~h}$ prior to the addition of insulin. Whole-cell extracts were analyzed by Western blotting with $\alpha \mathrm{G} \alpha \mathrm{q} / 11, \alpha \mathrm{cG} \beta$ or $\alpha \mathrm{G} \beta \mathrm{L}$ (representative blots are shown). (B) The linear portion of the cycle titration curve for actin and G $\beta$ L transcripts was determined as described in the Materials and Methods. (C) After 32 cycles, G $\beta$ L band intensities were normalized to those of actin after 25 cycles. Different letters represent differences between any two groups, whereas identical letters represent the fact that there are no differences $(n=4)$.

transcript-specific increase in RNase activity is prevented by actinomycin $\mathrm{D}$, indicating that gene transcription is required. Since the structural similarities between $G \beta L$ and POP3 suggest that the two proteins may possess similar actions, it is conceivable that insulin-induced changes in the stability of some transcripts, in particular PEPCK, may be influenced by G $\beta \mathrm{L}$.

The ability of insulin to upregulate $G \beta L$ protein and mRNA levels in 3T3-L1 adipocytes suggests that insulin is a potent regulator of $G \beta L$ production and imply that $G \beta L$ may contribute to the intracellular events associated with insulin receptor (IR) activation. Insulin-stimulated glucose transport, glycogen synthesis and cell growth are believed to occur primarily in response to the ligand-activated autophosphorylation of the IR beta subunits and the consequential phosphorylation and activation of cytosolic kinases and adapter proteins (Cheatham \& Kahn 1995). However, earlier studies on the mechanisms of IR signaling indicated that some actions of insulin were mediated, in part, by pertussis-toxin-sensitive G-proteins (Heyworth et al. 1986, Gawler et al. 1987, Pyne et al. 1989, Butler et al. 1996, Krieger-Brauer et al. 1997). Although G-proteins traditionally associate with seven-transmembrane domain receptors (Bourne 1997), more recent studies have demonstrated both structural and functional links between
G-proteins and the IR (Jo et al. 1992, 1993a, b, Moxham \& Malbon 1996, Krieger-Brauer et al. 1997, Zheng et al. 1998, Imamura et al. 1999). Therefore, some of the actions of insulin may be mediated by unconventional signaling events independent of the known IR signaling cascade. Although it remains to be determined whether GBL directly interacts with any of these known intermediates, the ability of insulin to raise $G \beta L$ production implies that it is nevertheless important to the actions of insulin.

\section{References}

Bhandari B, Saini KS \& Miller RE 1991 Glycerology 3-phosphate dehydrogenase gene expression in cultured 3T3-L1 adipocytes: regulation by insulin, dexamethasone and dibutyryl cAMP at the level of mRNA abundance, transcription and mRNA stability. Molecular and Cellular Endocrinology 76 71-77.

Bourne HR 1997 How receptors talk to trimeric G proteins. Current Opinion in Cell Biology 9 134-142.

Burn TC, Connors TD, Van Raay TJ, Dackowski WR, Millholland JM, Klinger KW \& Landes GM 1996 Generation of a transcriptional map for a 700-kb region surrounding the polycystic kidney disease type 1 (PKD1) and tuberous sclerosis type 2 (TSC2) disease genes on human chromosome 16p3.3. Genome Research 6 525-537.

Butler AP, Martinez LA \& Montgomery RL 1996 Involvement of a pertussis-toxin sensitive $G$ protein in the induction of gene expression by insulin. Cellular Signalling 8 475-480. 
Cheatham B \& Kahn CR 1995 Insulin action and the insulin signaling network. Endocrine Reviews 16 117-142.

Chirgwin JM, Przybyla AE, MacDonald RJ \& Rutter WJ 1979 Isolation of biologically active ribonucleic acid from sources enriched in ribonuclease. Biochemistry 18 5294-5299.

Christ B, Nath A, Bastian H \& Jungermann K 1988 Regulation of the expression of the phosphoenolpyruvate carboxykinase gene in cultured rat hepatocytes by glucagon and insulin. European Journal of Biochemistry 178 373-379.

Christ B, Nath A \& Jungermann K 1990 Mechanism of the inhibition by insulin of the glucagon-dependent activation of the phosphoenolpyruvate carboxykinase gene in rat hepatocyte cultures. Action on gene transcription, mRNA level and -stability as well as hysteresis effect. Biological Chemistry Hoppe-Seyler 371 395-402.

Garcia HI, Fenoglio J, Li Y, Lewis C, Panchenko MP, Reiner O, Smith TF \& Neer EJ 1996 Folding of proteins with WD-repeats: comparison of six members of the WD-repeat superfamily to the G protein beta subunit. Biochemistry 35 13985-13994.

Gawler D, Milligan G, Spiegel AM, Unson CG \& Houslay MD 1987 Abolition of the expression of inhibitory guanine nucleotide regulatory protein Gi activity in diabetes [published erratum appears in Nature 1987327 732]. Nature 327 229-232.

Goalstone ML \& Draznin B 1998 What does insulin do to Ras? Cellular Signalling 10 297-301.

Goalstone ML \& Draznin B 1999 Effect of insulin on farnesyltransferase gene transcription and mRNA stability. Biochemical and Biophysical Research Communications 254 243-247.

Hamm HE \& Gilchrist A 1996 Heterotrimeric G proteins. Current Opinion in Cell Biology 8 189-196.

Heise T, Krones A, Nath A, Jungermann K \& Christ B 1998 Parallel acceleration of phosphoenolpyruvate carboxykinase mRNA degradation and increase in ribonuclease activity induced by insulin in cultured rat hepatocytes. Biological Chemistry 379 875-883.

Heyworth CM, Grey AM, Wilson SR, Hanski E \& Houslay MD 1986 The action of islet activating protein (pertussis toxin) on insulin's ability to inhibit adenylate cyclase and activate cyclic AMP phosphodiesterases in hepatocytes. Biochemical Journal 235 145-149.

Imamura T, Vollenweider P, Egawa K, Clodi M, Ishibashi K, Nakashima N, Ugi S, Adams JW, Brown JH \& Olefsky JM 1999 $\mathrm{G}$ alpha-q/11 protein plays a key role in insulin-induced glucose transport in 3T3-L1 adipocytes. Molecular and Cellular Biology 19 6765-6774.
Iynedjian PB, Jotterand D, Nouspikel T, Asfari M \& Pilot PR 1989 Transcriptional induction of glucokinase gene by insulin in cultured liver cells and its repression by the glucagon-cAMP system. Journal of Biological Chemistry 264 21824-21829.

Jo H, Cha BY, Davis HW \& McDonald JM 1992 Identification, partial purification, and characterization of two guanosine triphosphate-binding proteins associated with insulin receptors. Endocrinology 131 2855-2862.

Jo H, Byer S \& McDonald JM 1993a Insulin stimulates association of a $41 \mathrm{kDa}$ G-protein (GIR41) with the insulin receptor. Biochemical and Biophysical Research Communications 196 99-106.

Jo H, Radding W, Anantharamaiah GM \& McDonald JM 19936 An insulin receptor peptide (1135-1156) stimulates guanosine 5 '-[gamma- thio]triphosphate binding to the $67 \mathrm{kDa}$ G-protein associated with the insulin receptor. Biochemical Journal 294 19-24.

Kozak M 1996 Interpreting cDNA sequences: some insights from studies on translation. Mammalian Genome 7 563-574.

Krieger-Brauer HI, Medda PK \& Kather H 1997 Insulin-induced activation of NADPH-dependent $\mathrm{H}_{2} \mathrm{O}_{2}$ generation in human adipocyte plasma membranes is mediated by Gialpha2. Journal of Biological Chemistry 272 10135-10143.

Moxham CM \& Malbon CC 1996 Insulin action impaired by deficiency of the G-protein subunit Gialpha2. Nature 379 840-844.

Neer EJ, Schmidt CJ, Nambudripad R \& Smith TF 1994 The ancient regulatory-protein family of WD-repeat proteins. Nature 371 297-300.

Pyne NJ, Heyworth CM, Balfour NW \& Houslay MD 1989 Insulin affects the ability of Gi to be ADP-ribosylated but does not elicit its phosphorylation in intact hepatocytes. Biochemical and Biophysical Research Communications 165 251-256.

van der Voorn L \& Ploegh HL 1992 The WD-40 repeat. FEBS Letters 307 131-134.

Zheng XL, Guo J, Wang H \& Malbon CC 1998 Expression of constitutively activated Gialpha2 in vivo ameliorates streptozotocininduced diabetes. Journal of Biological Chemistry 273 23649-23651.

Received 11 July 2000

Accepted 21 September 2000 